\title{
Catalytic Infrared Drying Effect on Tomato Slices Properties
}

\section{Abano $\mathrm{EE}^{1 *}$, Ma $\mathrm{HL}^{2,3}$, Qu WJ',3, Wang $\mathrm{PL}^{2}$, Wu BG ${ }^{2}$ and Pan $\mathrm{ZL}^{2}$}

${ }^{1}$ Department of Agricultural Engineering, School of Agriculture, University of Cape Coast, PMB, Cape Coast, Ghana

${ }^{2}$ Department of Food Science and Engineering, School of Food and Biological Engineering, Jiangsu University, 301 Xuefu Road, Zhenjiang 212013, China

${ }^{3}$ Jiangsu Provincial Key Laboratory for Physical Processing Of Agricultural Products, Jiangsu University, 301 Xuefu Road, Zhenjiang 212013, China

\begin{abstract}
In this study, the effect of distance between Far-Infrared Radiation (FIR) emitter and the surface of tomato slices and sample thickness on drying time, non-enzymatic browning, brightness, the ratio of redness to yellowness, ascorbic acid content, and lycopene content of the dried tomato slices was investigated. Three levels of distance $(38$ to $50 \mathrm{~cm})$, sample thickness $(7$ to 11 $\mathrm{mm}$ ) were used for the experiment. The desirability index technique was used to determine the ideal drying conditions that yield minimum drying time and non-enzymatic browning and maximum brightness color, redness to yellowness ratio, lycopene content, and ascorbic acid of drying of tomato slices. At the best conditions of $40.29 \mathrm{~cm}$ distance and $9.04 \mathrm{~mm}$ sample thickness, the drying time was $108 \pm 4$ minutes; the non-enzymatic browning index was $0.338 \pm 0.12$ Abs unit; the brightness was $40.43 \pm 2.29$; the ratio of redness to yellowness was $0.92 \pm 0.13$; the ascorbic acid content was $3.76 \pm 0.27 \mathrm{mg} / \mathrm{g}$ dry matter; and the lycopene content was $72.34 \pm 19.87 \mathrm{mg} / 100 \mathrm{~g}$ dry matter. These results demonstrate that FIR should be considered as an efficient drying method for tomato with respect to colour and ascorbic acid preservation, minimization of brown pigment formation and increment in lycopene content.
\end{abstract}

Keywords: Tomato slices; Drying; Lycopene; Ascorbic acid; Nonenzymatic browning; Colour; Response surface methodology

\section{Introduction}

Tomato (Lycopersicon esculentum) plays an important role in the diet of mankind. It provides diet with color, flavor, vitamin, and lycopene. The average tomato composition is: water $(94 \mathrm{~g} / 100$ $\mathrm{g})$, carbohydrate $(3.9 \mathrm{~g} / 100 \mathrm{~g})$, sugar $(2.6 \mathrm{~g} / 100 \mathrm{~g})$, dietary fiber $(1.2$ $\mathrm{g} / 100 \mathrm{~g})$, fat $(0.2 \mathrm{~g} / 100 \mathrm{~g})$, protein $(0.9 \mathrm{~g} / 100 \mathrm{~g})$, vitamins (mainly vitamin C: $0.014 \mathrm{~g} / 100 \mathrm{~g}$ ) [1]. Fresh tomatoes contain $94 \mathrm{~g} / 100 \mathrm{~g}$ water within a slightly soft cell wall structure, which is responsible for the fast deterioration at post-harvest. Therefore, appropriate processing method is required to prolong the shelf-life of tomatoes. Drying is among the methods for the purpose to make a high-quality product, which can be consumed directly or used as the ingredient for preparation of stews, soups, sauces, pizzas, etc. Among the various drying methods, the most common is the convectional air drying. However, this approach is usually long, energy intensive, and cause many undesirable changes to the dried product. One of the ways to shorten the drying time and to make high-quality product is to use far-infrared radiation (FIR) heating. This method is suitable for thinlayer drying of materials with large surface of exposure to radiation [2]. The FIR impinges on the material to be dried, penetrates it, and converts the IR energy into heat [3]. This causes the material to be heated intensely, and as a result, reduces the temperature gradient inside the material within a short time. The FIR energy is transferred from the heater to the product surface without heating the surrounding air [4]. Therefore, there is lesser energy consumption in FIR drying process. Previous studies have reported several advantages of FIR drying over the conventional hot air: high-heat transfer coefficient, high-energy efficiency, lesser air flows through the food material, short processing time, and low cost of energy requirement [2,5-7]. Applied occasional FIR heating and concluded that the color degradation was offset by a significant reduction in drying time. Shorter drying time with improved product quality was reported by other researchers $[8,9]$, when periodic FIR heating was applied. The FIR process can be done at the ambient temperatures because air is transparent. Many authors have investigated the FIR drying of onion slices [2], apple slices [6,10], wet olive husk [11], barley [12], potato [13], cashew kernel [14], and tomato residue [15]. Little information is available on FIR catalytic drying of tomato slices.

Therefore, in this study, the influence of distance from the FIR catalytic emitter and the surface of the tomato slices, and the thickness of the sample, on drying time (DT), non-enzymatic browning index (BI), color brightness $\left(\mathrm{L}^{*}\right)$, the ratio of redness to yellowness $\left(a^{*} / b^{*}\right)$, ascorbic acid content (AA), and lycopene content (LC) of the dried tomatoes. Optimization of the FIR drying conditions was performed using the desirability index technique to establish the best condition for minimum DT and $\mathrm{BI}$, and maximum values of $\mathrm{LC}, \mathrm{AA}, \mathrm{L}^{*}$, and $\mathrm{a}^{\star} / \mathrm{b}^{*}$ for FIR drying of tomatoes.

\section{Materials and Methods}

\section{Sample preparation}

The fresh tomatoes used in this study were tomatoes from the Hong Xiu hybrid No. one variety procured from Zhenjiang local market, China. Selection was based on visual assessment of uniform color and geometry. The tomato samples were washed under running tap water and stored in a refrigerator at a temperature of $4^{\circ} \mathrm{C}$ to slow down the physiological and chemical changes $[16,17]$. Prior to drying, the individual tomatoes were cut into slices with a machine (SS-250, SEP Machinery Company Ltd, Guangzhou, China) with an accuracy of $0.05 \mathrm{~mm}$. Uniform slices of diameters $(6.32 \pm 0.16 \mathrm{~cm})$ were subjected to dry without removing the epidermis and the seeds. The initial mean moisture content of $19.49 \pm 0.17 \mathrm{~kg}$ water/ dry weight $(95.12 \pm 0.04 \%$

*Corresponding author: Ernest Ekow Abano, Department of Agricultura Engineering, School of Agriculture, University of Cape Coast, PMB, Cape Coast, Ghana, Tel: +233 54 2404334; Fax: +233 3321 32709; E-mail: ekowabano@yahoo.com

Received February 17, 2014; Accepted March 24, 2014; Published April 03, 2014

Citation: Abano EE, Ma HL, Qu WJ, Wang PL, Wu BG, et al. (2014) Catalytic Infrared Drying Effect on Tomato Slices Properties. J Food Process Technol 5: 312. doi:10.4172/2157-7110.1000312

Copyright: (c) 2014 Abano EE, et al. This is an open-access article distributed under the terms of the Creative Commons Attribution License, which permits unrestricted use, distribution, and reproduction in any medium, provided the original author and source are credited. 
w.b) of the tomatoes was determined gravimetrically at $150^{\circ} \mathrm{C}$ for $24 \mathrm{~h}$. The initial average LC $(11.84 \pm 1.3 \mathrm{mg} / \mathrm{g}$ dry weight), AA (4.09 \pm 0.36 $\mathrm{mg} / \mathrm{g}$ dry weight), color $\left(\mathrm{L}^{*}: 39.49 \pm 0.2, \mathrm{a}^{*}: 31.08 \pm 0.12, \mathrm{~b}^{*}: 29.84 \pm 0.3\right.$, $\left.a^{\star} / b^{\star}: 1.04 \pm 0.01\right)$, and BI (0.052 \pm 0.002 Abs units) were determined according to the method described below for each determination.

\section{Drying equipment and procedure}

The tomato slices were dried in a laboratory-type flameless gas FIR catalytic dryer developed for the present study. The device comprises of a 60 by $30 \mathrm{~cm}$ rectangular heater (The Bruest, S1224, Kansas, USA), distance adjustable screws, drying chamber, pressure gauge, and online electronic balance (Sartorius 2200S, Germany). The dryer uses propane gas as the energy source after electrical heating for 5-15 minutes. Preliminary experiments conducted with this device revealed that variation of gas pressure has no effect on the temperature of the heater. In this dryer, the pressure and distance were controlled by regulating the pressure gauge and adjustable distance screws. Temperature of the heat source was measured with an infrared thermometer $(-50$ to $+480^{\circ} \mathrm{C}$ ) with an accuracy of $0.1^{\circ} \mathrm{C}$. A schematic view of the FIR catalytic dryer is shown in Figure 1.

The drying chamber of $600 \times 300 \times 600 \mathrm{~mm}$ was made from a stainless steel sheet of thickness $0.4 \mathrm{~mm}$. The outer sides of the chamber were covered with plywood sheet of $8 \mathrm{~mm}$ thickness having a single opening at the front. The specifications of the FIR device is as follows: 240 voltage infrared heater, $63 \mathrm{WC}$ orifices, 2.08 amps AC-DC, and 12,000 BTU@0-4500 FT.ALT input energy. A stainless steel meshed sample tray was placed on a two-rail platform below the FIR heater. The temperature of the FIR heater was measured with a hand-held infrared thermometer throughout the experiment, and was recorded to be $384.9 \pm 12.8^{\circ} \mathrm{C}$.

\section{Experimental procedure}

The device was run idle for $0.25 \mathrm{~h}$ to achieve a steady-state condition prior to each run. About $100 \mathrm{~g}$ of the tomato slices was put in thin layer on the sample tray with one slice not touching the other and placed in the drying chamber. Preliminary experiments placed at 20 and 29

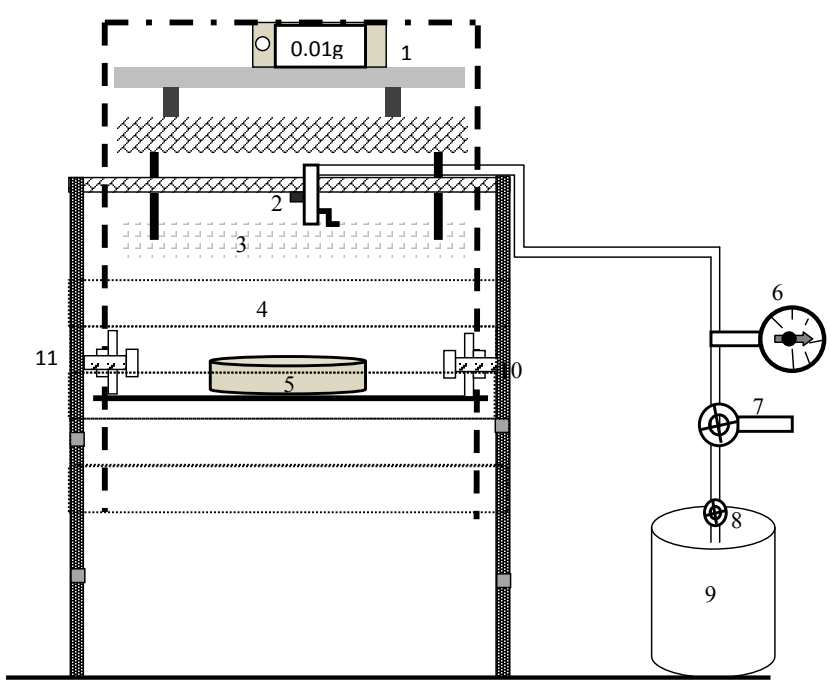

1---Mass balance, 2---Gas release button, 3--- Infrared heater, 4--- Drying chamber 5---meshed sample tray, 6--- Pressure gauge, 7---Pressure control, 8---Gas open/close valve, 9--- Gas cylinder, 10---Distance adjustment screws, 11---drying chamber cover

Figure 1: Schematic diagram of the laboratory FIR catalytic dryer. $\mathrm{cm}$ from the heat source at $2.0 \mathrm{kPa}$ gas pressure darkened the product. Therefore, the drying experiments were carried out at distance of 38 , $44,50 \mathrm{~cm}$ and sample thickness of 7, 9, $11 \mathrm{~mm}$ at gas pressure of 2.0 $\mathrm{kPa}$. During drying the mass of the samples were monitored online at an interval of 10 minutes. In this dryer, burning spots on the sample surfaces could easily be seen before all the moisture could be removed. Hence, the drying time was defined as the time required reducing the moisture content of the tomato from 19.49 to $0.7 \mathrm{~kg}$ water per $\mathrm{kg}$ dry weight. On completion of drying, the samples were cooled for 30 minutes in desiccators, wrapped with aluminum foil and stored in a freezer at $-18^{\circ} \mathrm{C}$ for further analysis.

\section{Experimental design}

The 3-level factorial Response Surface Method (RSM) was used to design the drying experiments. Three levels of two independent variables; $X_{1}$ (distance from the infrared heat source, $\mathrm{cm}$ ), and $\mathrm{X}_{2}$ (sample thickness, $\mathrm{mm}$ ) was generated for six response variables. The full model used to describe the response variable $\left(\mathrm{Y}_{\mathrm{r}}\right)$ involves the principal, interaction, and curvature effect as shown in Equation (1).

$$
Y_{r}=\hat{\mathrm{a}}_{0}+\hat{\mathrm{a}}_{1} X_{1}+\hat{\mathrm{a}}_{2} X_{2}++\mathrm{a}_{3} X_{1} X_{2}++\hat{\mathrm{a}}_{4} X_{1}{ }^{2}+\hat{\mathrm{a}}_{5} X_{2}{ }^{2}(1)
$$

Where $\beta_{0}, \beta_{1}, \beta_{2}, \beta_{3}, \beta_{4}, \beta_{5}$, are the regression coefficients, X1, X2, are the coded values of the independent variables, and $\mathrm{Yr}$ represents the response variables $\mathrm{DT}, \mathrm{LC}, \mathrm{AA}, \mathrm{BI}, \mathrm{L}^{\star}$, and $\mathrm{a}^{\star} / \mathrm{b}^{\star}$ of the dried product.

\section{Determination of ascorbic acid content}

The ascorbic acid of the fresh and the dried samples were determined volumetrically with $4 \%$ oxalic acid, using 2,6-dichlorophenolindophenol as described in Official Method of Analysis [18].

\section{Determination of lycopene content}

The lycopene content of the fresh and dehydrated samples was measured spectrophotometrically following the protocol of [19]. The pigment was repeatedly extracted with mortar and pestle from about $4 \mathrm{~g}$ of raw and $0.10 \mathrm{~g}$ of dried samples with acetone assisted with ultrasound until the residue was colorless. The acetone extract was transferred into a separating funnel containing $20 \mathrm{ml}$ petroleum ether and mixed gently. Then $20 \mathrm{ml}$ of $5 \%$ sodium sulphate solution was added, and the separating funnel shaken slowly. Another $20 \mathrm{ml}$ of petroleum ether was added to make up for any evaporated petroleum ether. The colored pigment noticed in the upper petroleum ether phase was separated and the lower phase re-extracted with more petroleum ether until colorless. The petroleum ether was washed with a little distilled water and poured into a brown bottle containing $10 \mathrm{~g}$ of anhydrous sodium sulphate and kept for at least 30 minutes. The petroleum ether was decanted into a $100 \mathrm{ml}$ volumetric flask through a cotton wool in a funnel. The sodium sulphate slurry was washed with petroleum ether until it was colorless and transferred into the volumetric flask. It was topped up to the mark with petroleum ether, and the absorbance measured in a spectrophotometer (UNICO 7200, Shanghai, China) with an accuracy of $0.0001 \mathrm{Abs}$ units at $503 \mathrm{~nm}$ with petroleum ether as the blank. The lycopene content (mg/100 g sample) was calculated using [Equation 2]

$$
L_{c}=\frac{31.206 \times \mathrm{Abs}_{503 n m}}{\mathrm{w}_{\mathrm{t}}}
$$

Where $\mathrm{L}_{c}$ is the lycopene content $(\mathrm{mg} / 100 \mathrm{~g}), A b s$ is the absorbance, and $\mathrm{w}_{\mathrm{t}}$ is the weight of the sample $(\mathrm{g})$

\section{Color measurement}

The color of the fresh and the dried product was measured in Hunter parameters with a colorimeter (DC-P3, Beijing, China). The 
raw tomatoes were milled for 2 minutes with kitchen type blender and passed through the $70 \mu \mathrm{m}$ sieve and poured into the cuvette holder. The colors of the dried samples were measured directly by focusing the light flux on the samples and covered with black cloth. The colorimeter was calibrated by placing the tip of the measuring light flux against the surface of the white and black calibration plates.

After calibration, three readings were recorded for the dried samples with the fresh tomato as the standard. The coordinate, $L^{*}$, measures the brightness value, which ranges between black (0) and white (100). The chromaticity coordinate, $a^{*}$, measures red when positive and green when negative, while the chromaticity coordinate, $b^{\star}$, measures yellow when positive and blue when negative. Values of $a^{*}$ and $b^{\star}$ range between -60 and +60 .

\section{Non-enzymatic browning determination}

A modified method of [20] was used to determine the nonenzymatic browning index (BI) of the dried tomatoes. To $50 \mathrm{~mL}$ of $60 \%$ ethanol $(\mathrm{v} / \mathrm{v}), 2 \mathrm{~g}$ of the powdered tomato sample was added and stirred. The mixture was allowed to stand for $12 \mathrm{~h}$, agitated, and then filtered through $0.45 \mu \mathrm{m}$ nylon filter membrane. The filtrate was topped up to the $50 \mathrm{~mL}$ mark, and the absorbance was measured at $440 \mathrm{~nm}$ with a spectrophotometer (UNICO 7200, Shanghai, China) against $60 \%$ ethanol as blank. The absorbance value obtained was used to indicate the extent of browning. All samples were extracted in duplicate.

\section{Optimization of the drying process}

The optimization of the drying process was performed using a multivariate response method called overall desirability index, DI [21] using Equation 3. The di represents the desirability index for each response variable $\left(\mathrm{Y}_{\mathrm{i}}\right)$, and it is a multi-criteria optimization approach used to show how worthwhile the various responses are.

$$
\mathrm{DI}=\left[\prod_{i=1}^{6} \mathrm{~d}_{\mathrm{i}}\left(\mathrm{Y}_{\mathrm{i}}\right)\right]^{1 / 6}
$$

The DI ranges between 0 and 1 with 0 being the least suitable whiles 1 is the most desirable. Maximization of DI value is the goal in optimization studies. The optimization process incorporates goals and priorities for the independent and response variables. For this study, the goal for the independent variables was at any level within the range of the design values. However, in the case of the response variables, the goal was minimum values of DT and $\mathrm{BI}$, and maximum values of $\mathrm{LC}$, AA content, $\mathrm{L}^{*}$, and $\mathrm{a}^{*} / \mathrm{b}^{*}$.

\section{Statistical analysis}

A second-order polynomial model was fitted to the mean values of the experimental results to get the regression equations with Design Expert 8.0.7.1 [22]. The statistical significance of the model terms was checked out at a probability of 0.05 . The accuracy of the model to describe the response variables was diagnosed against the normal probability plots of the residuals, the predicted versus actual plots, and the coefficients of determination $\left(\mathrm{R}^{2}\right)$ values. The 3-D surface plots for the factors were generated for the various responses.

\section{Result and Discussion}

\section{Effect of fir drying on drying time}

The results of the thirteen experiments performed according to the three-level factorial RSM are shown in Table 1. Kinetics of drying time of tomato slices with FIR energy was dependent on both the distance between the heat source and the surface of tomato slices as well as the thickness of the samples. The effect sample thickness and distance between the FIR energy emitter and the surface of tomato slices is evident (Figure 2). As expected, the principal effect of increasing the distance between the FIR emitter and the surface of tomato slices resulted in a significant increase in the DT of the tomato slices (Table 2 and Figure 2). Similarly, the principal and quadratic effect of an

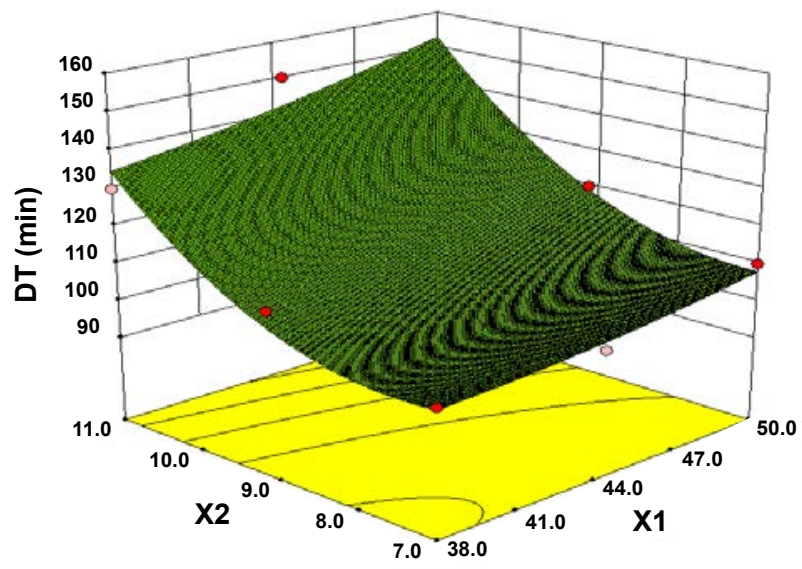

Figure 2: Effect of catalytic infrared intensity and sample thickness on response surface plot of drying time.

\begin{tabular}{|c|c|c|c|c|c|c|c|}
\hline Distance & Thickness & DT (min) & $L^{*}$ & $a^{*} / b^{*}$ & BI (Absunit) & AA (mg/g d.m) & LC (mg/ 100g d.m) \\
\hline 44 & 7 & 100 & 41.39 & 0.83 & 0.520 & 1.72 & 52.58 \\
\hline 44 & 9 & 110 & 42.58 & 0.78 & 0.279 & 3.58 & 73.02 \\
\hline 44 & 9 & 110 & 43.8 & 0.72 & 0.281 & 3.64 & 76.30 \\
\hline 38 & 11 & 130 & 45.04 & 0.66 & 0.410 & 2.43 & 74.48 \\
\hline 50 & 7 & 110 & 43.16 & 0.76 & 0.732 & 1.91 & 24.95 \\
\hline 44 & 9 & 110 & 41.44 & 0.87 & 0.278 & 3.58 & 76.30 \\
\hline 44 & 9 & 110 & 39.37 & 0.98 & 0.279 & 3.76 & 75.21 \\
\hline 44 & 9 & 110 & 38.97 & 1.00 & 0.281 & 3.64 & 73.02 \\
\hline 38 & 7 & 100 & 38.34 & 1.03 & 0.781 & 2.58 & 68.86 \\
\hline 38 & 9 & 110 & 38.06 & 1.06 & 0.413 & 3.54 & 40.02 \\
\hline 44 & 11 & 150 & 38.38 & 1.02 & 0.636 & 1.51 & 24.29 \\
\hline 50 & 9 & 120 & 38.72 & 0.97 & 0.472 & 3.15 & 60.48 \\
\hline 50 & 11 & 150 & 39.08 & 0.93 & 0.339 & 1.62 & 48.28 \\
\hline
\end{tabular}

Drying time (DT) in min; Color brightness $\left(L^{*}\right)$; Color ratio of redness to yellowness $\left(a^{*} / b^{*}\right)$; Nonenzymatic browning index $(B I)$ in absorbance units; Ascorbic acid content (AA) in $\mathrm{mg} / \mathrm{g}$ d.m, and Lycopene content (LC) in $\mathrm{mg} / 100 \mathrm{~g} \mathrm{~d} . \mathrm{m}$.

Table 1: Three-Level Factorial Design For Two Factors And Results Of $\mathrm{Dt}, L^{*}, A^{*} / B^{*}, \mathrm{Bi}, \mathrm{Aa}$ And Lc. 


\begin{tabular}{|c|c|c|c|l|l|}
\hline Source & $\begin{array}{c}\text { Coefficient } \\
\text { Estimate }\end{array}$ & $\begin{array}{c}\text { Sum of } \\
\text { squares }\end{array}$ & Df & F-value & $\begin{array}{c}\text { P-value } \\
\text { Prob }>\text { F }\end{array}$ \\
\hline Intercept $\left(\beta_{0}\right)$ & 111.03 & & & & \\
\hline Model & & 3154.80 & 5 & 36.17 & $<0.0001^{*}$ \\
\hline$X_{1}\left(\beta_{1}\right)$ & 6.67 & 266.67 & 1 & 15.28 & $<0.0058^{*}$ \\
\hline$X_{2}\left(\beta_{2}\right)$ & 20.00 & 2400.00 & 1 & 137.56 & $<0.0001^{*}$ \\
\hline$X_{1} X_{2}\left(\beta_{3}\right)$ & 2.50 & 25.00 & 1 & 1.43 & $0.2702^{* *}$ \\
\hline$X_{12}\left(\beta_{4}\right)$ & 1.38 & 5.25 & 1 & 0.30 & $0.6002^{* *}$ \\
\hline$X_{22}\left(\beta_{5}\right)$ & 11.38 & 357.64 & 1 & 20.50 & $0.0027^{*}$ \\
\hline
\end{tabular}

*Significant; ** not significant; lack of fit is not significant at $P$ value $>0.0$ Table 2: ANOVA of drying time for infrared dried tomato slices by response surface quadratic model.

increase in sample thickness so increased DT significantly. Depending on the drying condition, the time required reducing moisture content of tomatoes from 19.49 to $0.7 \mathrm{~kg}$ water / $\mathrm{kg}$ dry matter was between 100 and 150 minutes. This means that there were significant savings in time as distance between the FIR emitter and surface of the tomato slices and sample thickness was decreased. Variations in the estimated coefficients show that there were different relative effects of the independent variables. The effect of sample thickness was more pronounced on DT than the effect of the distance from the FIR heater [Equation 4]. The lowest sample thickness and distance between the infrared energy emitter and the surface of tomato slices gave the least DT. The interaction effect of distance and sample thickness was an unimportant model term on the DT. The quadratic effect of the sample thickness was, however, significant. The result depicted that as distance increases, the temperature of the sample decreases, and as a result decreases the removal of moisture from the surface, which, consequently prolongs the processing time. Similarly, with the increase in the sample thickness, the distance for moisture transport from the centre to the surface of the slices is widened, thereby resulting in an extension in DT.

$$
Y_{D T}=111.03+6.67 X_{1}+20.0 X_{2}+2.5 X_{1} X_{2}+1.38 X_{1}^{2}+11.38 X_{2}^{2}
$$$$
\left(\mathrm{R}^{2}=0.9627\right)
$$

A similar effect of distance on the DT for FIR drying of apple slices [6] and onion slices [2] were reported.

The higher value of $\mathrm{R}^{2}$ of 0.9627 depicts that a higher proportion of the experimental variability was explained by the RSM model. The suitability of the model was further verified with the normal probability plot of the DT residuals (Figure 3a) and the predicted versus actual DT plot (Figure 3b). The lack of fit test was also not significant, which further validates the model.

\section{Effect of FIR Drying on Color}

Color change is another quality criterion for assessing the quality of dried products. The closer it is to the fresh tomatoes, the better it is preferred by consumers. Higher values of $L^{\star}$ and $a^{\star} / b^{\star}$ are desirable in dried products [23]. The effect of the independent variables on $L^{*}$ and $a^{\star} / b^{*}$ is shown in Figures 4 and 5.

Generally, the effect of distance and sample thickness on the $L^{*}$ was not statistically significant within the range of distance and sample thickness studied (Equation 5 and Table 3 ) even though the luminance improved with increasing these factors (Figure 4).

A similar trend was observed for the $a^{\star} / b^{\star}$ values (Equation 6 and Table 3). The increase in distance and sample distance decreased the $a^{\star} / b^{*}$ values insignificantly. When the color values of dried tomato slices were compared with the fresh $\left(L^{*}: 39.49, a^{*}: 31.08, b^{*}: 29.84\right.$, $\left.a^{\star} / b^{*}: 1.04\right)$, there were enhancement in brightness and general reduction in $a^{*} / b^{*}$. The reduction in $a^{*} / b^{*}$ ratio were smaller $(4.9 \%)$ compared with hot air dried tomato slices (11.04\%) [24]. The decrease of the $a^{*} / b^{*}$ suggests less Maillard reaction. Siriamornpun et al. [25] dried marigold using FIR heating and reported color degradation even though the extent of degradation was less in FIR drying than freeze and hot air drying. The color changes in tomato slices may be caused by the destruction of the pigment present in tomatoes [26]. The color of the final dried tomatoes may be strongly related to the carotenoid lycopene [27]. This is because lycopene, which is carotenoids, gives the red-color of dried tomatoes. Degradation of $a^{\star} / b^{\star}$ pigment of the dried tomatoes might show decreased bioactivity of the dried products. The color of the FIR dried tomatoes suggests that this method of drying can preserve bioactive compounds and activities than hot air method. The results were consistent with what Al-Muhtaseb et al. [28] reported for drying tomato pomace. The normal probability plots and simulated versus actual $\mathrm{L}^{\star}$ and $\mathrm{a}^{\star} / \mathrm{b}^{\star}$ are displayed in Figure 6 .

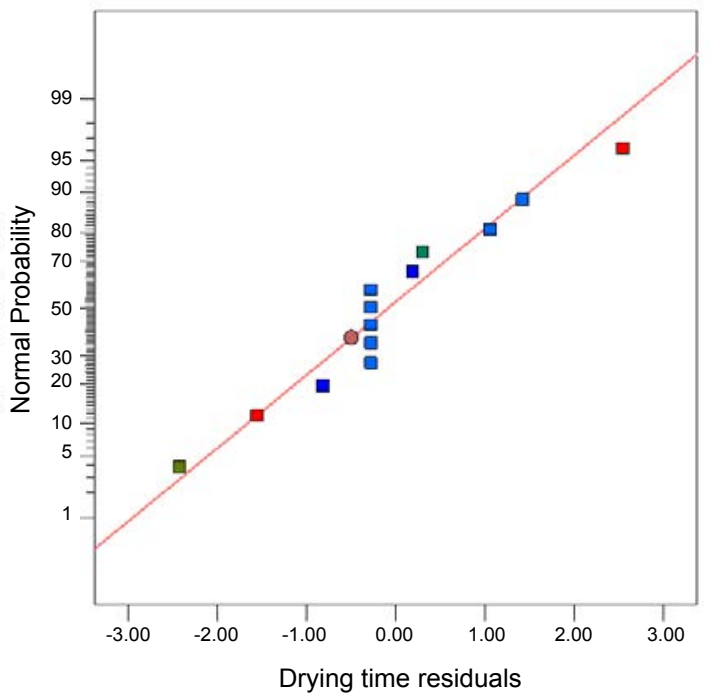

(a)

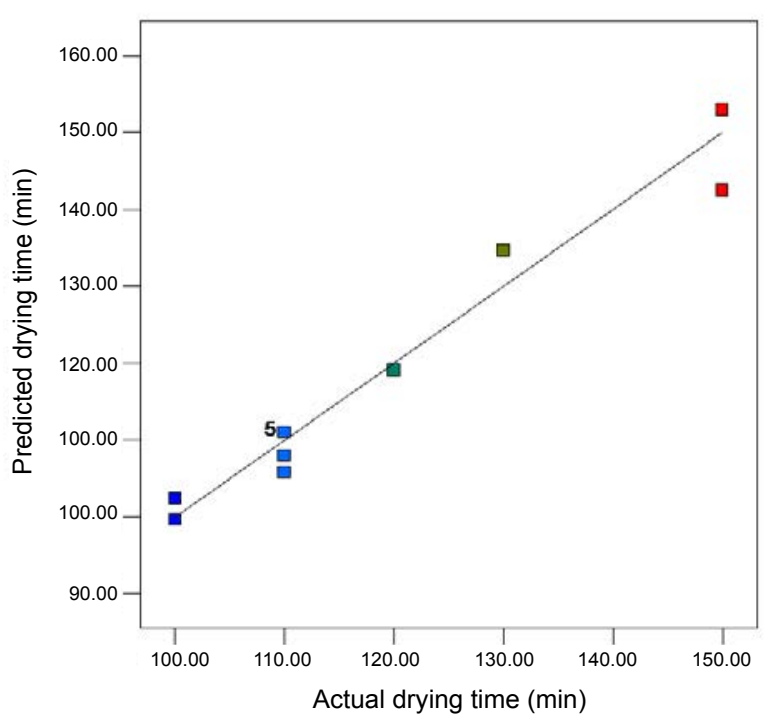

(b)

Figure 3: (a) Normal probability plot of the drying time residuals; (b) Predicted versus actual drying time 


$$
\begin{gathered}
Y_{\left(L^{*}\right)}=40.63-0.080 X_{1}-0.060 X_{2}-2.69 X_{1} X_{2}-0.74 X_{1}^{2}+0.76 X_{2}^{2} \\
(\mathrm{R} 2=0.4595) \\
\mathbf{Y}_{\frac{\mathbf{a}^{*}}{\mathbf{b}^{*}}}=0.90-0.015 \mathbf{X}_{1}-0.001667 \mathbf{X}_{2}+0.14 \mathbf{X}_{1} \mathbf{X}_{2}+0.036 \mathbf{X}_{1}^{2}-0.054 \mathbf{X}_{2}^{2}
\end{gathered}
$$$$
(\mathrm{R} 2=0.3987)
$$

\section{Effect of FIR drying on non-enzymatic browning}

Non-enzymatic browning is another quality indicator in drying. Whereas browning is desirable in some processed foods, it is undesirable in dried tomatoes. The extent of browning is mainly attributed to the color changes resulting from Maillard reactions in the tomatoes $[29,30]$. Expectedly, the combined effect of increases in

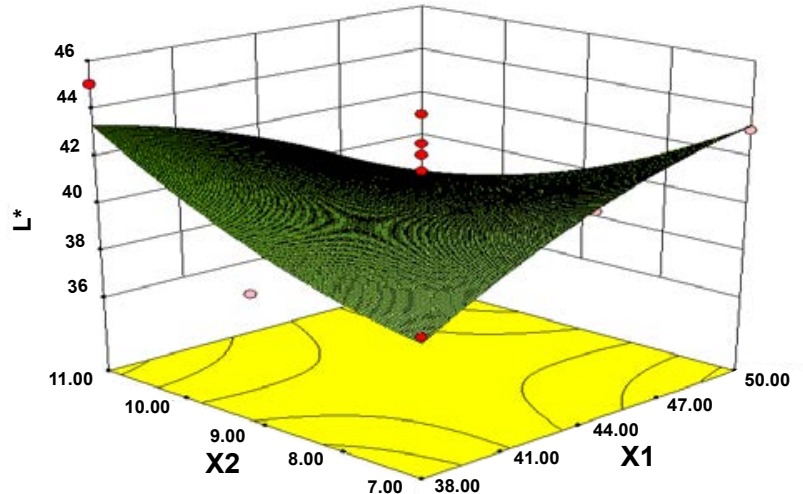

Figure 4: Effect of catalytic infrared intensity and sample thickness on response surface plot of brightness color of dried tomatoes.

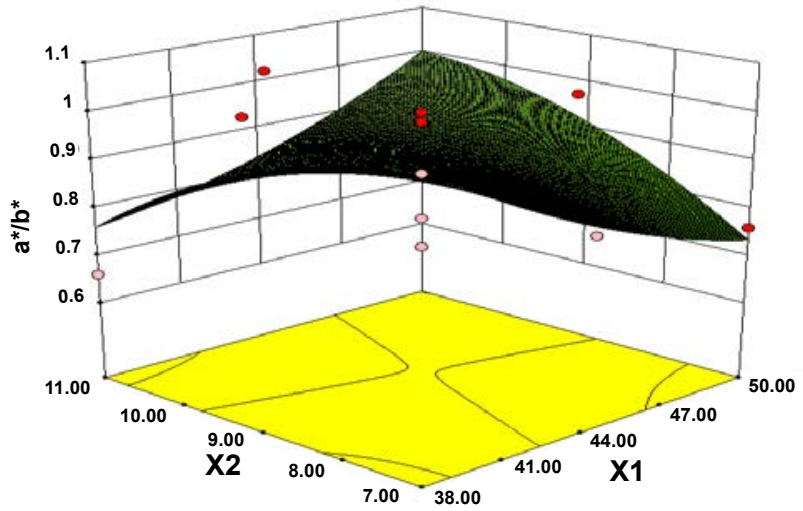

Figure 5: Effect of catalytic infrared intensity and sample thickness on on response surface plot ratio of redness to yellowness of dried tomatoes. these conditions decreased the BI values (Figure 7, Equation 7) with the quadratic effect being significant (Table 4). The decreasing trend of $\mathrm{BI}$ depicts that the rate of brown pigment formation diminished with increasing the factors and were mainly caused by thermal effect of the drying air. For this present study, the BIs were in the range of 0.279 0.781. In comparison with the raw tomatoes (BI of 0.052), there was browning in all the dried samples with the majority of the BIs below 0.60 absorbance unit. The browning indexes in the range of 0.585 0.684 were reported at temperature between 50 and $90^{\circ} \mathrm{C}$ by [20]. In a visual assessment of dried tomato samples by 11 randomly selected panels, browning absorbance equal to 0.6 was considered critical [20]. Based on the above, without doubt, more than $77 \%$ of the samples dried under the experimental conditions studied would be acceptable to consumers. The occurrence of the browning might be attributed to the reactions between nitrogenous constituents and reducing sugars, nitrogen-bearing constituents and organic acids, and sugars and organic acids in the tomatoes [30,31]. The validity of the model is shown in Figures 8a and 8b. The lack of fit test was significant, which indicate that the overall mean of the BI values is a better predictor than the quadratic model.

$$
Y_{B I}=0.30-0.10 X_{1}-0.11 X_{2}-0.0055 X_{1} X_{2}+0.078 X_{1}^{2}+0.21 X_{2}^{2}
$$

$(\mathrm{R} 2=0.7206)$

\section{Effect of IR Drying on Ascorbic Acid Content}

Principally, the distance of the tomato from the FIR heat source was significant for the ascorbic acid content of the final samples (Table 5). On the contrary, AA was affected insignificantly by its sample thickness. The increase in distance and sample thickness resulted in AA decrease, but the effect of distance was higher than sample thickness (Equation 8). Quadratically, the effect of sample thickness on AA content was very profound and showed statistical significance (Figure 9). The relative percentage degradation after infrared heating was between 8 and 63\%. Comparatively, the FIR degradation of AA was higher than what Sokhansanj and Jayas [32] reported for industrial drying of fruits and vegetables (i.e. between $10 \%$ and 50\%).

There are complexities surrounding AA content degradation in drying of fruits and vegetables [33]. As distance and sample thickness increases, it takes a longer time to dry the sample. There is therefore, a long-time exposure of the samples to air temperature and as a result decreased the AA content. In onion [34], okra [35], and potato [36,37] drying, sample thickness was observed to affect AA retention significantly. Timoumia et al. [38] studied infrared dried Red Chief apple slices at $40-70^{\circ} \mathrm{C}$ and reported a pseudo-first-order degradation rate for AA content with an increase in temperature. Marfil et al. [39]

\begin{tabular}{|c|c|c|c|c|c|c|c|c|c|}
\hline Source & $\begin{array}{l}\text { Coefficient } \\
\text { Estimate } L^{*}\end{array}$ & $\begin{array}{c}\text { Sum } \\
\text { of squares } L^{*}\end{array}$ & Df & F-value $L^{*}$ & $\begin{array}{l}\text { P-value } \\
\text { Prob }>F L^{*}\end{array}$ & $\begin{array}{c}\text { Coefficient } \\
\text { Estimate } a^{*} / b^{*}\end{array}$ & $\begin{array}{c}\text { Sum } \\
\text { of squares } a^{*} / b^{*}\end{array}$ & F-value $a^{*} / b^{*}$ & $\begin{array}{c}\text { P-value } \\
\text { Prob }>\mathrm{F} \mathbf{a}^{\star} / \mathbf{b}^{*}\end{array}$ \\
\hline Intercept $\left(\beta_{0}\right)$ & 40.63 & & & & & 0.90 & & & \\
\hline Model & & 31.35 & 5 & 1.19 & $0.4016^{* *}$ & & 0.083 & 0.93 & $0.5157^{* *}$ \\
\hline$X_{1}\left(\beta_{1}\right)$ & -0.080 & 0.0388 & 1 & 0.0073 & $0.9344^{* *}$ & -0.015 & 0.00135 & 0.075 & $0.7915^{\star *}$ \\
\hline$X_{2}\left(\beta_{2}\right)$ & -0.065 & 0.025 & 1 & 0.0048 & $0.9466^{* *}$ & -0.001667 & 0.001655 & 0.00093 & $0.9765^{\star *}$ \\
\hline$X_{1} X_{2}\left(\beta_{3}\right)$ & -2.69 & 29.05 & 1 & 5.51 & $0.0512^{* *}$ & 0.14 & 0.073 & 4.07 & $0.0833^{\star *}$ \\
\hline$X_{12}\left(\beta_{4}\right)$ & -0.74 & 1.50 & 1 & 0.28 & $0.6105^{\star *}$ & 0.036 & 0.003655 & 0.20 & $0.6650^{* *}$ \\
\hline$X_{2}^{2}\left(\beta_{5}\right)$ & 0.76 & 1.59 & 1 & 0.30 & $0.5998^{* *}$ & -0.054 & 0.007941 & 0.44 & $0.5266^{\star *}$ \\
\hline
\end{tabular}
investigated the ascorbic acid degradation of air dried tomato halves at temperatures of 50,60 , and $70^{\circ} \mathrm{C}$ at speed of $1.0 \mathrm{~m} / \mathrm{s}$ and reported that the ascorbic acid in the tomatoes after dehydration reduced from

*Significant; ** not significant; lack of fit is not significant at $P$ value $>0.05$

Table 3: ANOVA of color $L^{*}$ and $a^{*} / b^{*}$ for the infrared dried tomatoes by response surface quadratic model. 
Citation: Abano EE, Ma HL, Qu WJ, Wang PL, Wu BG, et al. (2014) Catalytic Infrared Drying Effect on Tomato Slices Properties. J Food Process Technol 5: 312. doi:10.4172/2157-7110.1000312

6(a)

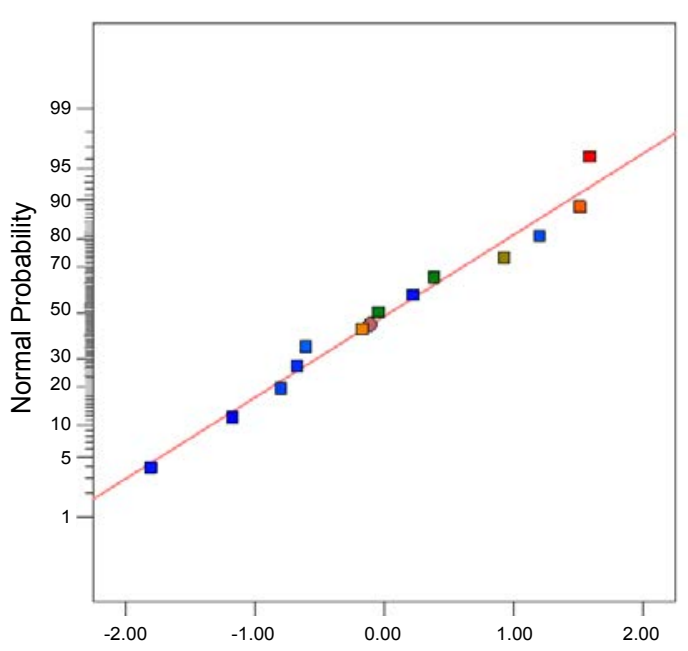

6(b)

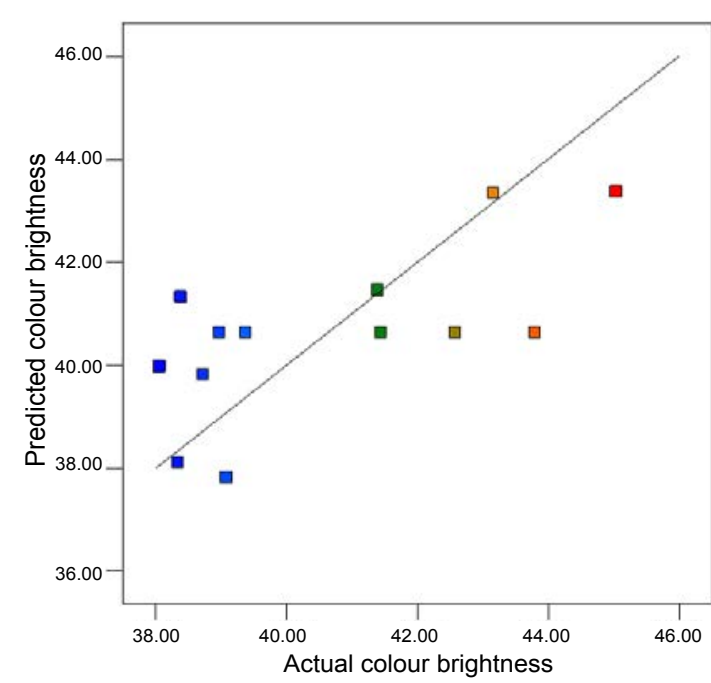

$6(\mathrm{c})$

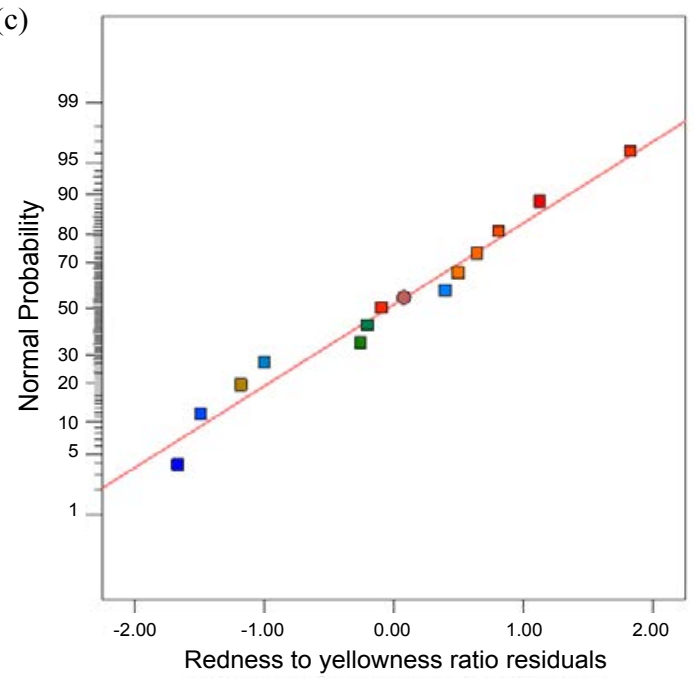

$6(d)$

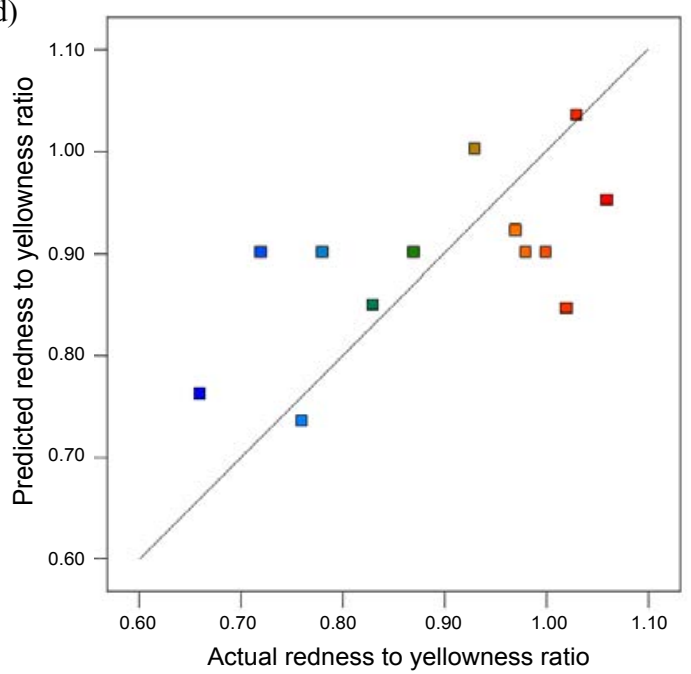

Figure 6: (a) Normal probability plot of the $L^{*}$; (b) Predicted versus actual plot of $L^{*}$.,(c) Normal probability plot of $a^{*} / b^{*}$ residuals; (d) Predicted versus actual plot of the $a^{*} / b^{*}$ residuals.

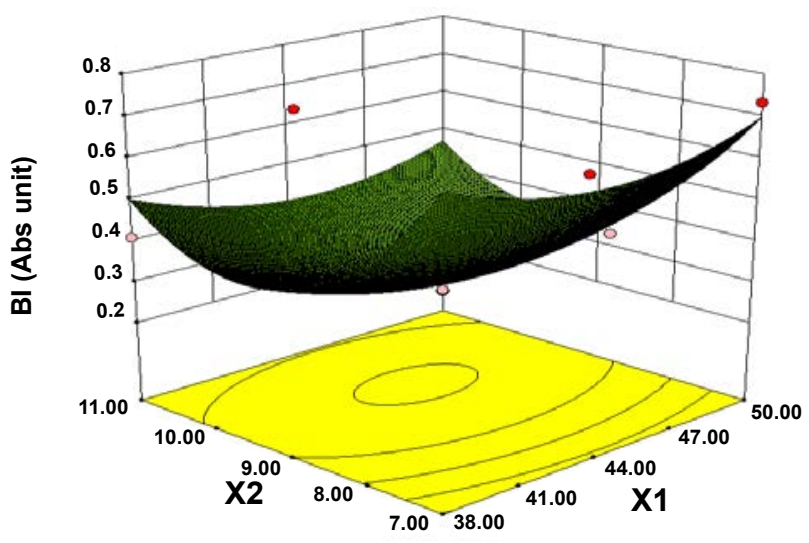

Figure 7: Effect of catalytic distance and sample thickness on $\mathrm{BI}$ of dried tomatoes.

\begin{tabular}{|c|c|c|c|l|l|}
\hline Source & $\begin{array}{c}\text { Coefficient } \\
\text { Estimate }\end{array}$ & $\begin{array}{c}\text { Sum } \\
\text { of squares }\end{array}$ & Df & F-value & $\begin{array}{c}\text { P-value } \\
\text { Prob>F }\end{array}$ \\
\hline Intercept $\left(\beta_{0}\right)$ & 0.30 & & & & \\
\hline Model & & 0.28 & 5 & 3.61 & $0.0620^{* *}$ \\
\hline$X_{1}\left(\beta_{1}\right)$ & -0.010 & 0.00062 & 1 & 0.04 & $0.8471^{* *}$ \\
\hline$X_{2}\left(\beta_{2}\right)$ & -0.010 & 0.23 & 1 & 4.53 & $0.0708^{* *}$ \\
\hline$X_{1} X_{2}\left(\beta_{3}\right)$ & -0.0055 & 0.000121 & 1 & 0.000823 & $0.9320^{* *}$ \\
\hline$X_{12}\left(\beta_{4}\right)$ & 0.078 & 0.017 & 1 & 1.08 & $0.3323^{* *}$ \\
\hline$X_{22}\left(\beta_{5}\right)$ & 0.21 & 0.13 & 1 & 8.17 & $0.0244^{*}$ \\
\hline
\end{tabular}

*Significant; ** not significant; lack of fit is significant at $P$ value $>0.05$

Table 4: ANOVA of BI for the infrared dried tomato slices by response surface quadratic model.

$4.00 \pm 0.30 \mathrm{mg} / \mathrm{g}$ to $2.19 \pm 0.24 \mathrm{mg} / \mathrm{g}$ dry matter, representing $35 \%$ reduction. In pear drying, Mrad et al. [40] found AA to decrease as air temperature increased in the range of $30-70^{\circ} \mathrm{C}$ and attributed this to the occurrence of irreversible oxidative reactions during drying. There was a similar degradation in AA content when Erenturk et al. [41] dried rosehip in the temperature range of $50-80^{\circ} \mathrm{C}$ at constant air velocity 


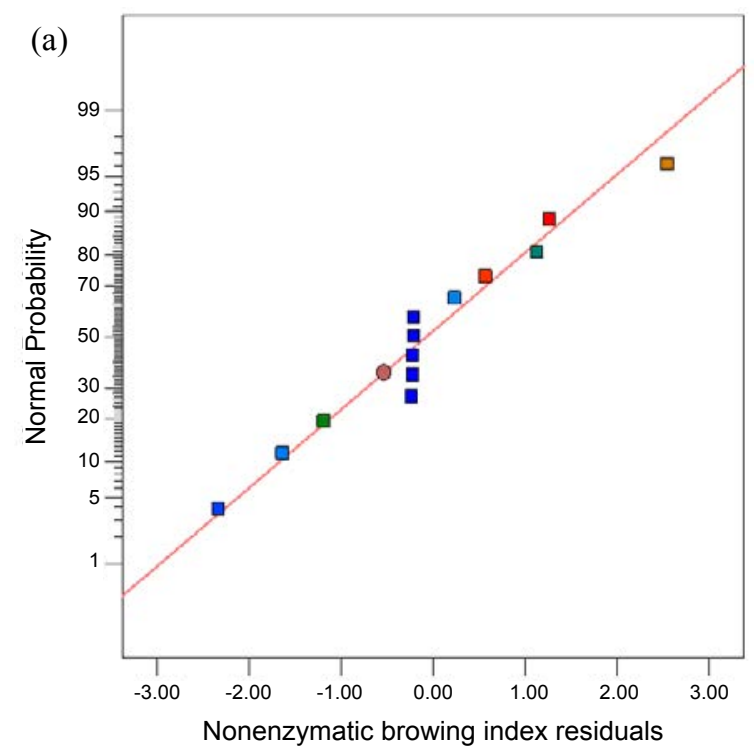

(b)

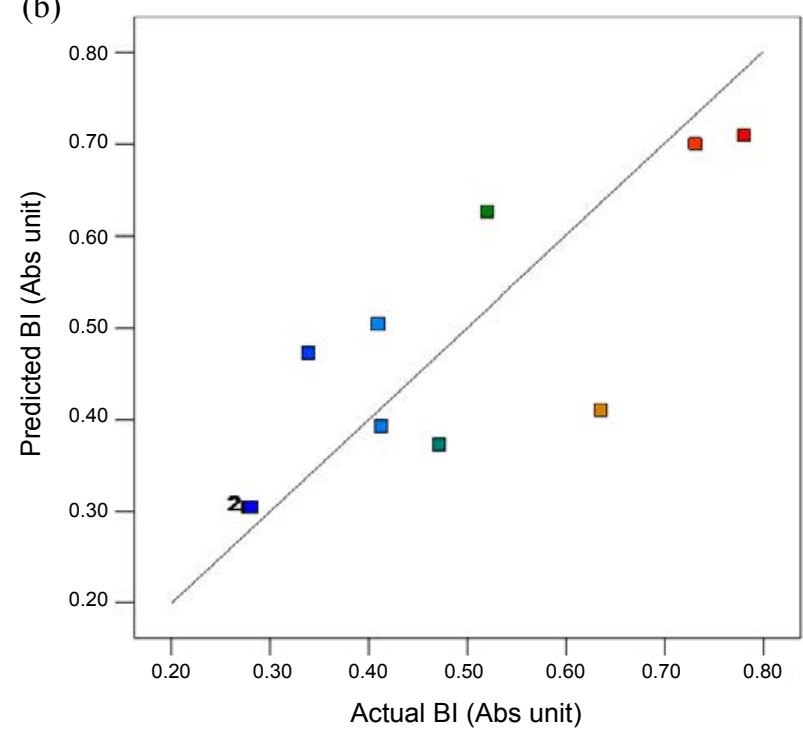

Figure 8: (a) Normal probability plot of the $\mathrm{BI}$; (b) Predicted versus actual plot of $\mathrm{BI}$.

\begin{tabular}{|c|c|c|c|c|c|}
\hline Source & $\begin{array}{c}\text { Coefficient } \\
\text { Estimate }\end{array}$ & $\begin{array}{c}\text { Sum } \\
\text { of squares }\end{array}$ & Df & F-value & $\begin{array}{c}\text { P-value } \\
\text { Prob }>\mathbf{F}\end{array}$ \\
\hline Intercept $\left(\beta_{0}\right)$ & 3.53 & & & & \\
\hline Model & & 8.89 & 5 & 23.92 & $0.0003^{*}$ \\
\hline$X_{1}\left(\beta_{1}\right)$ & -0.31 & 0.58 & 1 & 7.84 & $0.0265^{*}$ \\
\hline$X_{2}\left(\beta_{2}\right)$ & -0.11 & 0.070 & 1 & 0.95 & $0.3629^{* *}$ \\
\hline$X_{1} X_{2}\left(\beta_{3}\right)$ & -0.035 & 0.0049 & 1 & 0.066 & $0.8048^{* *}$ \\
\hline$X_{12}\left(\beta_{4}\right)$ & 0.098 & 7.35 & 1 & 0.36 & $0.5674^{* *}$ \\
\hline$X_{2}{ }^{2}\left(\beta_{5}\right)$ & -1.63 & 0.52 & 1 & 98.87 & $<0.0001^{*}$ \\
\hline
\end{tabular}

*Significant; ** not significant; lack of fit is significant at $P$ value $>0.05$

Table 5: ANOVA of AA content for FIR dried tomato slices.

and humidity ratio of $1.67 \mathrm{~m} / \mathrm{s}$ and $0.005 \mathrm{~kg}$ moisture $/ \mathrm{kg}$ dry matter respectively. Compared with the initial AA content of $4.09 \pm 0.48 \mathrm{mg} / \mathrm{g}$ of the fresh tomatoes used for the study, it can be concluded that the reduction of AA was caused by thermal due to the high temperature used rather than oxidative damage. The normal probability plot of the residuals and the predicted versus experimental AA content used to check the suitability of the model are displayed in Figures 10a and 10b.

$$
Y_{A A}=3.53-0.31 X_{1}-0.11 X_{2}-0.035 X_{1} X_{2}+0.098 X_{1}^{2}-1.63 X_{2}^{2}
$$

( R2=0.9447)

\section{Effect of FIR drying on lycopene content}

The distance between the FIR heat source and the surface of the samples was an important parameter for LC (Figure 11, Equation 9, Table 6). The enlargement in sample thickness increased the LC but not significantly. The LC measured in this study was between 24.29 and $76.30 \mathrm{mg} / 100 \mathrm{~g}$ dry matter. Compared with the LC of the fresh samples (11.84 mg/100 dry matter) there was significant improvement in the LC after infrared heating. In drying of most vegetables, increases in lycopene content have been reported [42-44]. Lycopene degradation depends on many factors, including processing temperature. The increase in bio-accessible lycopene content is primarily due to the increased release of phytochemicals from the matrix to make it more accessible in the extraction process [43]. Additionally, the increment may be explained by an increased release of lycopene from the cell, skin and insoluble fibre of tomato [45]. Lycopene of the fresh tomato isomerizes from trans-form into the cis-lycopene as a result of thermal treatment or degrades into a colorless form [46]. Common heat treatments of tomato products do not result in a shift in the distribution of cis-lycopene isomers [47]. Thus, the increase in lycopene content reported in this study may be due to actual increase of lycopene due to concentration effect as a result of drying rather than a progressive conversion from its trans form to a less strongly colored, less intensely absorbing cis form. Siriamornpun et al. [25] studied the LC of a marigold flower after Freeze Drying (FD), Hot Air (HA) drying, and combined FIR-HA and reported that the FIR-HA samples had the highest amount of lycopene $(58.7 \mathrm{mg} / 100 \mathrm{~d} . \mathrm{m})$, followed by the HA (51.2 $\mathrm{mg} / 100 \mathrm{~g}$ d.m), and then the FD samples ( $48.7 \mathrm{mg} / 100 \mathrm{~d} . \mathrm{m})$. In comparison with the fresh marigold flowers used by Siriamornpun et al. [25], the lycopene of FIR-HA samples increased by $54 \%$, whereas that of HA and FD samples respectively increased by 34 and $28 \%$. The normal probability plot of the LC residuals (Figure 12a), the predicted versus actual LC plots (Figure 12b), and the lack of fit test further shows that the overall mean of the $\mathrm{LC}$ is a better predictor.

$$
\boldsymbol{Y}_{L C}=69.22-8.28 \boldsymbol{X}_{1}+0.11 \boldsymbol{X}_{2}+4.43 \boldsymbol{X}_{1} \boldsymbol{X}_{2}-5.10 \boldsymbol{X}_{1}^{2}-16.91 \boldsymbol{X}_{2}^{2}
$$

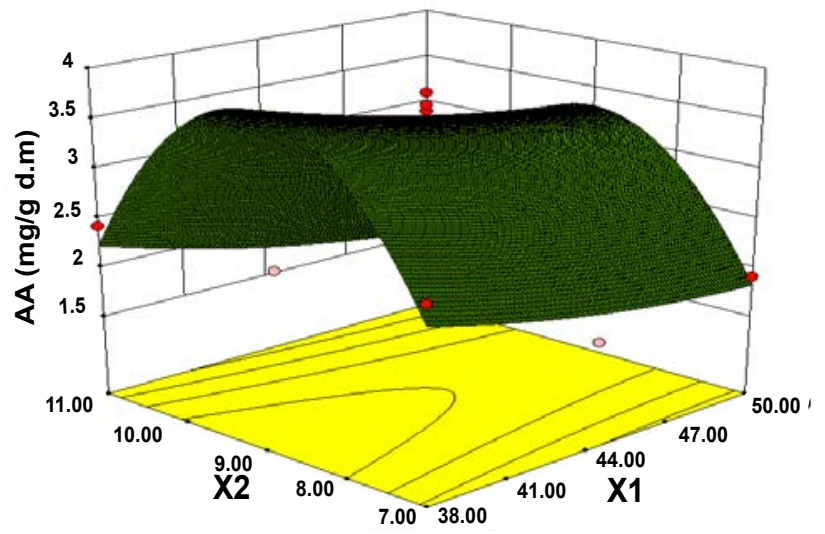

Figure 9: Effect of catalytic FIR distance and sample thickness on AA content. 
Citation: Abano EE, Ma HL, Qu WJ, Wang PL, Wu BG, et al. (2014) Catalytic Infrared Drying Effect on Tomato Slices Properties. J Food Process Technol 5: 312. doi:10.4172/2157-7110.1000312

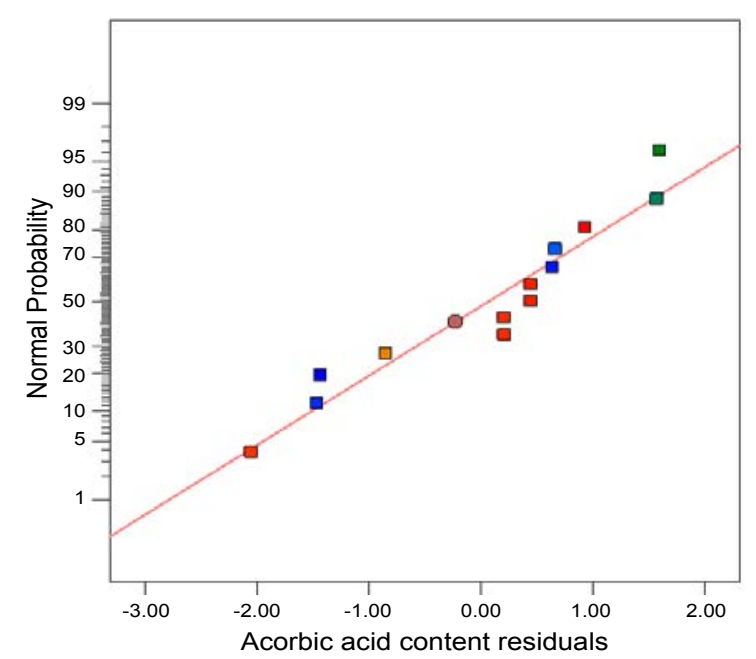

(a)

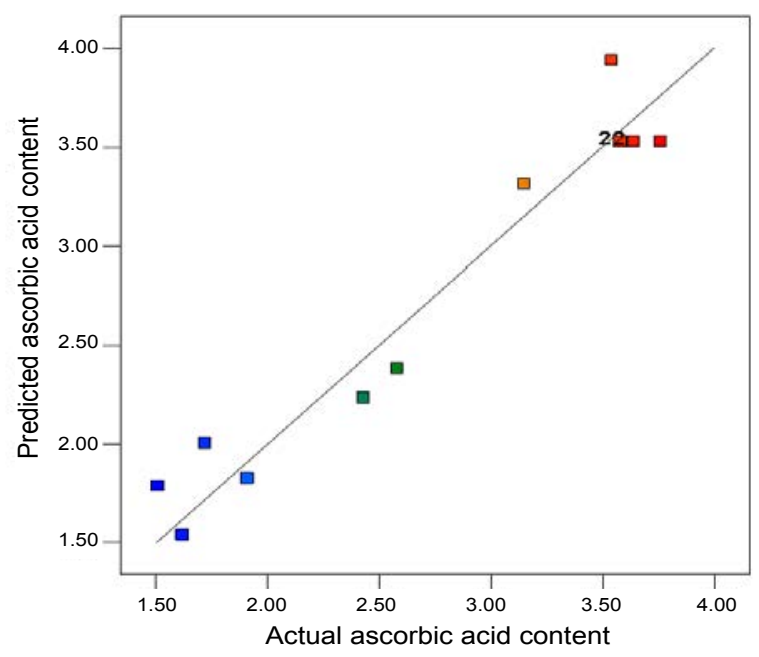

(b)

Figure 10: (a) Normal probability plot of AA content residuals; (b) Predicted versus actual plot of AA content.
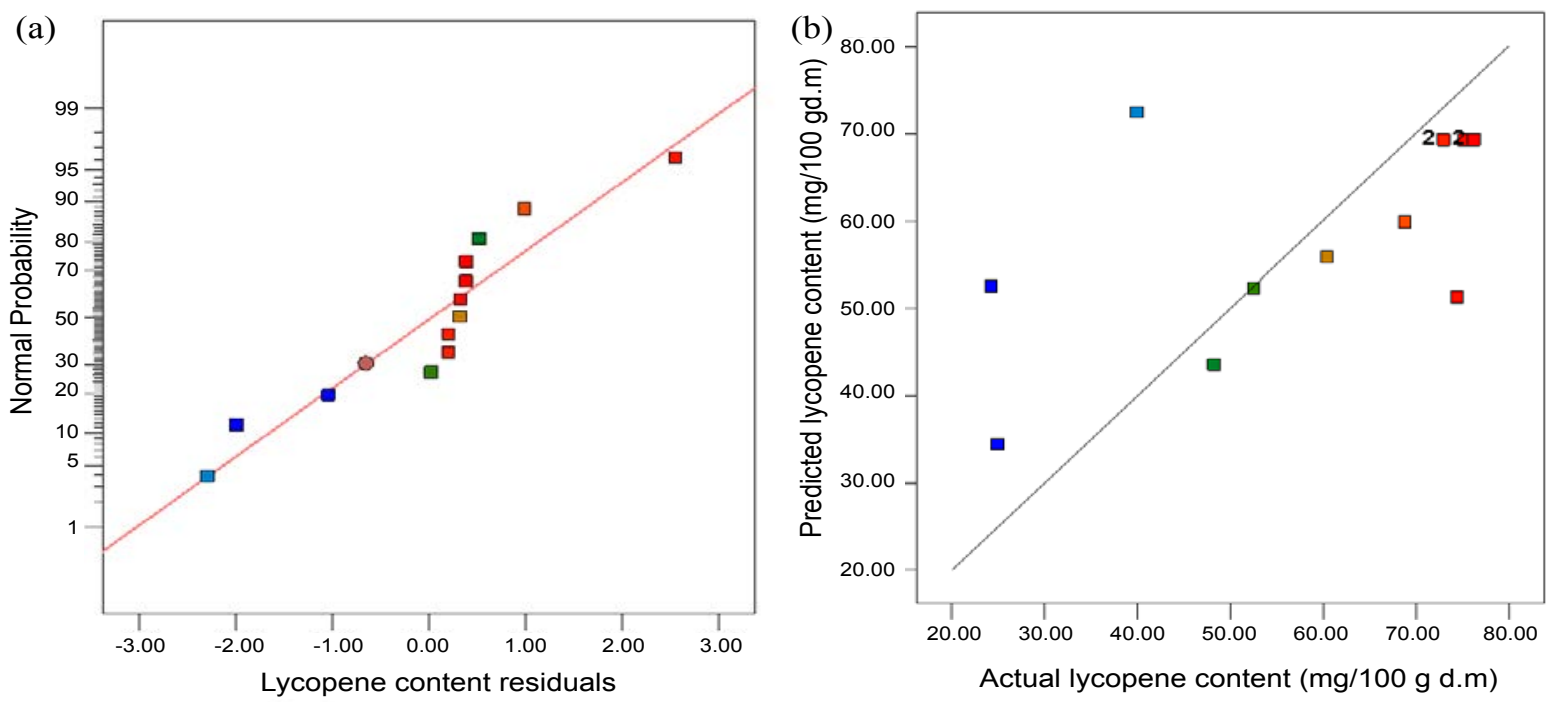

Figure 12: (a) Normal probability plot of the lycopene content residuals; (b) Predicted versus actual of the lycopene content.

\begin{tabular}{|c|c|c|c|c|c|}
\hline Source & $\begin{array}{c}\text { Coefficient } \\
\text { Estimate }\end{array}$ & $\begin{array}{c}\text { Sum } \\
\text { of squares }\end{array}$ & Df & F-value & $\begin{array}{c}\text { P-value } \\
\text { Prob>F }\end{array}$ \\
\hline Intercept $\left(\beta_{0}\right)$ & 69.22 & & & & \\
\hline Model & & 1710.06 & 5 & 36.17 & $0.5473^{\star *}$ \\
\hline$X_{1}\left(\beta_{1}\right)$ & -8.28 & 410.85 & 1 & 15.28 & $0.03417^{*}$ \\
\hline$X_{2}\left(\beta_{2}\right)$ & 0.11 & 0.073 & 1 & 137.56 & $0.9896^{* *}$ \\
\hline$X_{1} X_{2}\left(\beta_{3}\right)$ & 4.43 & 78.41 & 1 & 1.43 & $0.6693^{* *}$ \\
\hline$X_{12}\left(\beta_{4}\right)$ & -5.10 & 71.83 & 1 & 0.30 & $0.6825^{\star *}$ \\
\hline$X_{2}^{2}\left(\beta_{5}\right)$ & -16.91 & 790.21 & 1 & 20.50 & $0.2001^{* *}$ \\
\hline
\end{tabular}

*Significant; ** not significant; lack of fit is significant at $P$ value $>0.05$

Table 6: ANOVA of LC for FIR drying of tomato slices by response surface quadratic model.

\section{Optimization of the drying parameters}

The affirmation of the location of the optimal FIR drying conditions was done using the concept of overall desirability index in Equation 3. The maximum predicted DT, BI, $\mathrm{L}^{\star}, \mathrm{a}^{\star} / \mathrm{b}^{\star}, \mathrm{AA}$ and $\mathrm{LC}$, and $\mathrm{AA}$,

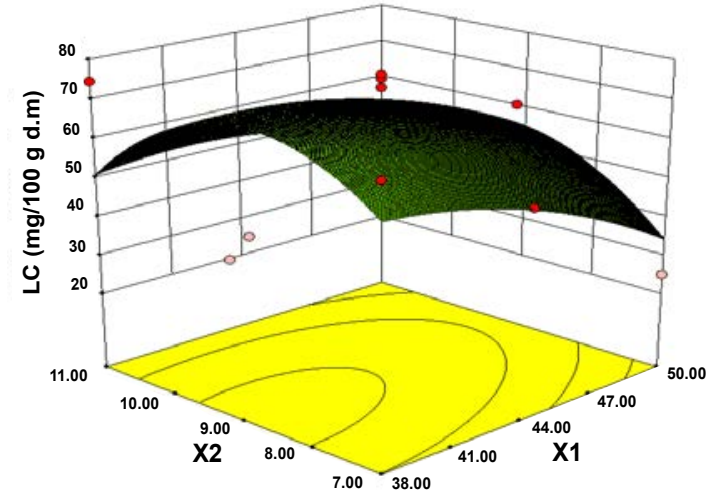

Figure 11: Effect of catalytic FIR distance and sample thickness on the LC of dried tomatoes. 


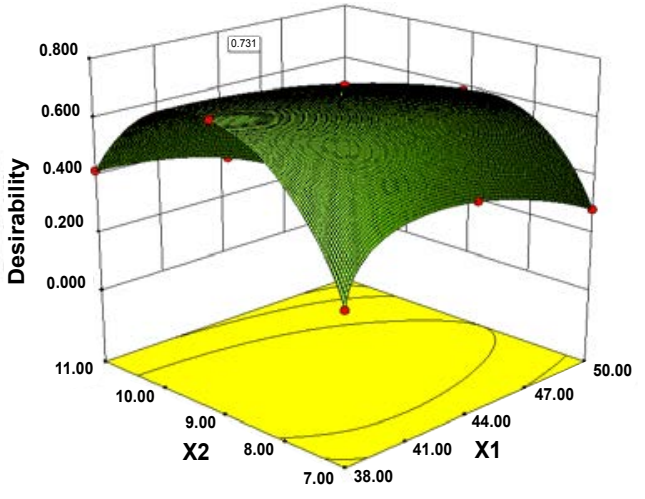

Figure 13: Effect of catalytic FIR and sample thickness on response surface plot of the desirability index for the optimal drying condition.

were $118.63 \mathrm{~min}, 0.662 \mathrm{Abs}$ unit, 46.40, $4.46 \mathrm{mg} / \mathrm{g} \mathrm{d} . \mathrm{m}$, and 124.02 $\mathrm{mg} / 100 \mathrm{~g}$ d.m respectively. These simulated values are closer to their corresponding experimental values of $150 \mathrm{~min} \mathrm{DT}, 0.781 \mathrm{BI}, 45.04 \mathrm{~L}^{*}$ , $1.03 \mathrm{a}^{\star} / \mathrm{b}^{\star}, 3.64 \mathrm{mg} / \mathrm{g}$ dry matter AA content, and $76.3 \mathrm{mg} / 100$ dry matter LC.

The desirability of the responses gave an overall desirability of 0.731 (Figure 13). The results predicted with $95 \%$ confidence in the range of the independent variables gave optimal distance between the infrared radiation emitter and surface of the sample as $40.29 \mathrm{~cm}$, and sample thickness as $9.04 \mathrm{~mm}$. At this optimum condition, the DT, BI, $\mathrm{L}, \mathrm{a}^{*} / \mathrm{b}^{*}$, AA and LC were found to be $107.8 \mathrm{~min}, 0.338$ Abs unit, 40.43 , $0.92,3.76 \mathrm{mg} / \mathrm{g}$ dry matter and $72.34 \mathrm{mg} / 100 \mathrm{~g}$ dry matter respectively.

\section{Conclusion}

The study demonstrated that catalytic infrared drying conditions affect specific quality properties of tomatoes. The distance between the infrared radiation emitter source and the surface of tomato slices and the thickness of tomato slices affected the drying time, non-enzymatic browning index, and brightness, ratio of redness to yellowness, ascorbic acid content, and lycopene content of dried tomatoes. Within the range of distances investigated, the increase in distance significantly decreased the drying time, ascorbic acid content, but insignificantly increased the lycopene content and the ratio of redness to yellowness. The combined effect of increasing the independent variables decreased the non-enzymatic browning indexes. With increase in thickness of the samples, the drying time increased significantly, the lycopene increased insignificantly, but decreased the non-enzymatic browning index, redness to yellowness ratio, ascorbic acid content, and color brightness values insignificantly. The prediction of the desirability model based on $95 \%$ confidence in the range of the independent variables gave the optimal drying conditions as $40.29 \mathrm{~cm}$ distance, and $9.04 \mathrm{~mm}$ sample thickness. The present study has provided useful information for industrial drying of tomatoes and for tomato powder for food preparation and pharmaceutical formulations. The results offer optimized drying conditions for the food industry to improve on quality of dried product.

\section{Acknowledgement}

The authors wish to extend their appreciation to the Open Fund of Jiangsu Provincial Key Laboratory for Physical Processing of Agricultural Products (JAPP2010-6), the Jiangsu Province Science and Technology Support Project (BE2011382), the Jiangsu University Graduate Research Innovation Program
(CXZZ12_0700), the Jiangsu University Student Scientific Research Project (11A346), the Jiangsu University Student Practice Innovation Training Program and the Priority Academic Program Development (PAPD) of Jiangsu Higher Education Institutions for their financial support toward the study.

\section{Reference}

1. USDA (2012) United States Department of Agriculture. Agriculture research service. Tomatoes, red, ripe, raw, year round average. National nutrient database for standard reference.

2. Sharma GP, Verma RC, Pathare PB (2005) Thin-layer infrared radiation drying of onion slices. J. Food Eng 67: 361-366.

3. Ginzburg A S (1969) Application of infrared radiation in food processing Chemical process engineering series. London: Leonard Hill.

4. Jones P (1992) Electromagnetic wave energy in drying processes. Drying 92 : 114-136.

5. Togrul H (2005) Simple modeling of infrared drying of apple slices. Journal of food Engineering 71: 311-323.

6. Nowak D, Lewicki PP (2004) Infrared drying of apple slices. Innovative Food Sci and Emerging Technologies 5: 353-360.

7. Chua KJ, Chou SK, Mujumdar AS, Ho JC, Hon CK (2004) Radiant-convective drying of osmotic treated agro-products:Effect on drying kinetics and product quality. Food Control 15: 145-158.

8. Carroll MB, Churchill SW (1986) Anumerical study of periodic on-off versus continuous heating by conduction. Numerical Heat Transfer 10: 297-310.

9. Dostie M, Seguin JN, Maure D, Ton That QA, Chatingy R (1989) Preliminary measurements on the drying of thick porous materials by combinations of intermittent IR and continuous convection heating. Drying 89: 513-520.

10. Togrul H (2006) Suitable drying model for infrared drying of carrot. Journal of food Engineering 77: 610-619.

11. Ruiz Celma A, Rogas S, López-Rodríguez F (2008) Mathematical modeling of thin-layer infrared drying of wet olive husk. Chemical Engineering and Processing, Process Intensification 47: 1810-1818.

12. Afzal TM, Abe T (2000) Simulation of moisture changes in barley during far infrared radiation drying. Computers and Electronics in Agriculture 26: 137-145

13. Afzal TM, Abe T (1998) Diffusion in potato during far infrared radiation drying J Food Eng 37: 353-365.

14. Hebbar HU, Rastogi NK (2001) Mass transfer during infrared drying of cashew kernel. Journal of Food Engineering 47: 1-5

15. Celma AR, Cuadros F, López-Rodríguez F (2009) Characterization of industrial tomato by-products from infrared drying process. Food Bioprod Process 87 282-291.

16. Karaaslan SN, Tuncer IK (2008) Development of a drying model for combined microwave-fan-assisted convection drying of spinach. Biosystem. Eng 100: 44-52.

17. Maskan M (2001) Drying, shrinkage, and rehydration characteristics of kiw fruits hot air and microwave drying. J Food Eng 48: 177-182.

18. AOAC (1990) Official methods of analysis of the association of official analytical chemists. Association of Official Analytical Chemists, Washington DC, USA.

19. Ranganna S (1976) In: Manual of Analysis of Fruits and Vegetable Products McGraw Hill, New Delhi p 77.

20. Cernîsev S (2010) Effect of conventional and multistage drying processing on non-enzymatic browning in tomato. J Food Eng 96: 114-118.

21. Myers RH, Montgomery DC (2002) Response Surface Methodology: Process and Product Optimization Using Designed Experiments. John Wiley \& Sons, New York, NY.

22. Design Expert (2010) Design Expert 8.0.7.1. Stat-Ease, Inc. Minneapolis, MN.

23. Arslan D, Özcan MM (2008) Evaluation of drying methods with respect to drying kinetics, mineral content, and colour characteristics of rosemary leaves. Energy Convers. Manage 49: 1258-1264.

24. Abano EE, Ma H, Qu W (2011) Influence of Air Temperature on the Drying Kinetics and Quality of Tomato Slices. J Food Process Technol 2: 1-9.

25. Siriamornpun S, Kaisoona O, Meesoc N (2012) Changes in colour, antioxidant 
Citation: Abano EE, Ma HL, Qu WJ, Wang PL, Wu BG, et al. (2014) Catalytic Infrared Drying Effect on Tomato Slices Properties. J Food Process Technol 5: 312. doi:10.4172/2157-7110.1000312

activities and carotenoids (lycopene, b-carotene, lutein) of marigold flower (Tagetes erecta L.) resulting from different drying processes. J functional foods 4: 757-766.

26. Wanyo P, Siriamornpun S, Meeso N (2011) Improvement of quality and antioxidant properties of dried mulberry leaves with combined far-infrared radiation and air convection in Thai tea process. Food and Bioproducts Processing 89: 22-30.

27. Rao AV, Agarwal S (1999) Role of lycopene as antioxidant carotenoid in the prevention of chronic diseases: A review. Nutr Res 19: 305-323.

28. Al-Muhtaseb AH, Al-Harahsheh M, Hararah M, Magee TRA (2010) Drying characteristics and quality change of unutilized-protein rich tomato pomace with and without osmotic pre-treatment. J Indus Crops \& Prod 31: 171-177.

29. Porretta S, Sandei L (1991) Determination of 5-HMF in tomato products proposed of a rapid HPLC method and its comparison with the colorimetric method. Food Chem 39: 51-57.

30. Zanoni B, Peri C, Nani R, Lavelli V (1999) Oxidative heat damage of tomato halves as affected by drying. Food Res Int 31: 395-401.

31. Muratore G, Rizzo V, Licciardello F, Maccarone E (2008) Partial dehydration of cherry tomato at different temperature, and nutritional quality of the products. Food Chem 111: 887-891.

32. Sokhansanj S, Jayas DS (1995) Drying of food stuffs. Handbook of industria drying. New York, Marcel Dekker Inc.

33. Santos PHS, Silva MA (2010) Retention of Vitamin C in Drying Processes of Fruits and Vegetables-A Review, Dry. Technol 26: 1421-1437.

34. Adam E, Mühlbauer W, Esper A, Wolf W, Spiess W (2000) Quality changes of onion (Allium cepa L.) as affected by the drying process. Nahrung 44: 32-37.

35. Adom KK, Dzogbefia VP, Ellis WO (1997) Combined effect of drying time and slice thickness on the solar drying of okra. J Sci of Food and Agric 73: 315-320.

36. Wang J, Chao Y (2003) Effect of gamma irradiation on quality of dried potato. Rad Phys \& Chem 66: 293-297.
37. Wang J, Du Y (2005) The effect of c-ray irradiation on the drying characteristics and final quality of dried potato slices. Int J Food Sci Technol 40: 75-82.

38. Timoumia S, Mihoubia D, Zagroubab F( 2007) Shrinkage, vitamin C degradation and aroma losses during infra-red drying of apple slices. LWT 40: 1648-1654.

39. Marfil PHM, Santos EM, Telis VRN (2008) Ascorbic acid degradation kinetics in tomatoes at different drying conditions. Food Sci. Technol 41: 1642-1647.

40. Mrad ND, Boudhrioua N, Kechaou N, Courtois F (2012) Influence of air drying temperature on kinetics, physiochemical properties, total phenolic content and ascorbic acid of pears. Food Bioprod. Process. 90: 433-441.

41. Erenturk S, Gulaboglu MS, Gultekin S (2005) The effect of cutting and drying medium on the vitamin $\mathrm{C}$ content of rosehip during drying. J Food Eng 68: 513-518.

42. Tonucci LH, Holden J M, Beecher GR, Khachik F, Davis CS, et al. (1995) Carotenoid content of thermally processed tomato-based food products. J Agric and Food Chem 43: 579-586.

43. Dewanto V, Wu X, Adom KK, Liu RH (2002) Thermal processing enhances the nutritional value of tomatoes by increasing total antioxidant activity. J Agric Food Chem 50: 3010-3014.

44. Nguyen ML, Schwartz SJ (1998) Lycopene stability during food processing Proc Soc Exp Biol Med 218: 101-105.

45. Shi J, Le Maguer M (2000) Lycopene in tomatoes: chemical and physical properties affected by food processing. Crit Rev Food Sci Nutr 40: 1-42.

46. Sharma S K, Le Maguer M (1996) Kinetics of lycopene degradation in tomato pulp solids under different processing and storage conditions. Food Res Intern 29: 309-315.

47. Goula AM, Adamopoulos KG, Chatzitakis PC, Nikas VA (2006) Prediction of lycopene degradation during a drying process of tomato pulp. J Food Eng 74 $37-46$ 